\title{
Performance of Pseudapanteles dignus (Hymenoptera: Braconidae), a Natural Enemy of Tuta absoluta (Lepidoptera: Gelechiidae) in Eggplant
}

\author{
Nadia G. Salas Gervassio, María G. Luna, ${ }^{1}$ Franco D’Auro, and Norma E. Sánchez
}

Centro de Estudios Parasitológicos y de Vectores (CEPAVE), CONICET-UNLP, Boulevard 120 e/ 60 y 64, (1900) La Plata, Argentina and 'Corresponding author, e-mail: lunam@cepave.edu.ar

Subject Editor: Eric Riddick

Received 25 July 2017; Editorial decision 28 November 2017

\begin{abstract}
Pseudapanteles dignus (Muesebeck; Hymenoptera: Braconidae) is an American endoparasitoid that attacks the South American tomato leafminer Tuta absoluta (Meyrick; Lepidoptera: Gelechiidae). The interaction between $P$. dignus and T. absoluta in tomato (Solanum lycopersicum L.; Solanales: Solanaceae) crops has demonstrated that this enemy exhibits some desirable ecological traits as an effective biological control agent of this pest. With the aim of extending the use of $P$. dignus to other solanaceous crops, laboratory experiments were carried out to assess some life history traits and the parasitism efficiency when parasitizing T. absoluta larvae fed on eggplant (Solanum melongena L.; Solanales: Solanaceae). Rearings and experiments were conducted at $25 \pm 2{ }^{\circ} \mathrm{C}, \approx 70 \% \mathrm{RH}$, and $14: 10$ (L:D) h photoperiod, and T. absoluta was fed with eggplant. P. dignus developmental times of immature stages were lower ( $5 \mathrm{~d}$ ) on $\mathrm{S}$. melongena than on S. lycopersicum. The female did not exhibit a pre-reproductive period, and its oviposition period lasted longer ( $4 \mathrm{~d}$ ) than that determined in tomato plants. Adult longevity was ca. $24 \mathrm{~d}$ for both sexes. Females produced ca. 61 cocoons during their lives and the maximum daily percentage of parasitism was $50 \%$ at the first day of adult emergence. Functional response of $P$. dignus on eggplant was density-independent of the host density offered, as in tomato plant, and the instantaneous attack rate ( $\left.a^{\prime}\right)$ was 0.24 attacked larvae/ available larvae, in $24 \mathrm{~h}$. Our results indicate that although there are differences, $P$. dignus would have a similar performance in eggplant and tomato in terms of its efficacy in the control of T. absoluta.
\end{abstract}

Key words: South American tomato leafminer, Solanaceae, parasitoid, biocontrol agent, Solanum melongena

The tomato leafminer Tuta absoluta (Meyrick; Lepidoptera: Gelechiidae) native to the South America has been reported as causing significant economic losses to tomato (Solanum lycopersicum L.; Solanales: Solanaceae) production in many countries in Europe, Africa and Asia (Parra and Zuchi 2004, Desneux et al. 2011, Luna et al. 2015, Ponti et al. 2015). Its spread is also threatening North American crops (USDA 2011). Besides tomato, T. absoluta feeds on other host plants from the Solanceae family, including crop and non-crop species (Galarza 1984, Estay 2000, Desneux et al. 2010, USDA 2011, Bawin et al. 2015, Salas Gervassio et al. 2016). Particularly, after its initial detection in tomato crops in Spain in 2006 (Urbaneja et al. 2007), it has been found causing economic damage in eggplant (Solanum melongena L.; Solanales: Solanaceae) crops in southern Italy (Speranza et al. 2009, Tropea Garzia et al. 2009). Some years later, in Africa, Mohamed et al. (2012) reported severe losses in S. melongena crops of Sudan, and El Arnaouty and Kortam (2012) recorded its presence in plantations in Egypt.
Studies carried out in Argentina demonstrated that T. absoluta is attacked by a diverse complex of natural enemies in tomato crops (Colomo et al. 2002; Sánchez et al. 2009; Luna et al. 2015; Savino et al. 2012, 2016), being Pseudapanteles dignus (Muesebeck; Hymenoptera: Braconidae) the main larval parasitoid (Luna et al. 2007). More recently, Salas Gervassio et al. (2016) found that T. absoluta populations can also reach up to $33 \%$ of natural parasitism in protected eggplant crops in northeastern Buenos Aires province, Argentina.

P. dignus is a solitary koinobiont endoparasitoid. The parasitoid female is able to attack all T. absoluta larval instars but exhibits better performance when parasitizing mid-instar larvae. After completing its development, the larva leaves the dead host and the pupa is covered by a white cocoon. This parasitoid species has been reported parasitizing few gelechiid species in the Americas (Cardona and Oatman 1971, Fernández-Triana et al. 2014). Research on the P. dignus-T. absoluta interaction in tomato crops has demonstrated that the parasitoid has some desirable ecological traits to be 
considered an effective biocontrol agent of T. absoluta in open-field and protected tomato crops (Luna et al. 2007, Sánchez et al. 2009, Nieves et al. 2015). Among these, it shows seasonal synchronization with host populations, aggregative response to host density, and an instantaneous attack rate greater than the intrinsic growth rate of the host.

Although it is known that $P$. dignus establishes a persistent interaction with T. absoluta in eggplant (Salas Gervassio et al. 2016), similar to that registered in tomato by Nieves et al. (2015), more information is necessary to confirm the potential of this parasitoid for the biological control of T. absoluta on eggplant crops.

The objective of this study was to determine some life history traits of $P$. dignus and its parasitism efficiency against T. absoluta on eggplant. We assessed developmental times of immature stages, adult longevity, daily parasitism rate, and functional response under laboratory conditions.

\section{Materials and Methods}

\section{Source of Plants and Insects}

T. absoluta and $P$. dignus were originally collected from commercial eggplant organic crops (var. Barcelona $F_{1}$ ) in northern Buenos Aires province, Argentina. Colonies of both species were maintained in a walk-in growth chamber at $25 \pm 2^{\circ} \mathrm{C}, \approx 70 \% \mathrm{RH}$, and $14: 10$ (L:D) $\mathrm{h}$ photoperiod. Individuals used in this study were $\mathrm{F}_{5}$ progeny of founder colonies. Seedlings (var. Barcelona $F_{1}$ ), grown in 3-liter plastic pots with peat and perlite, and fertilized every $15 \mathrm{~d}$ (Nitrofoska foliar PS COMPO: www.compo-expert.com, Santiago, Chile) $(1.5 \mathrm{mg}$ ), were used to feed T. absoluta in our colony and in the trials conducted in this study. Plants were held in a pesticidefree greenhouse, and to avoid their infestation with any possible insects present in the environment, they were placed inside BIOQUIP (Rancho Dominguez, CA) meshed cages $(35 \mathrm{~cm}$ in width, $35 \mathrm{~cm}$ in length, $60 \mathrm{~cm}$ in height) until seedlings reached approximately $20 \mathrm{~cm}$ of height. T. absoluta adults were kept in voile- meshed cages $(40 \times 40 \times 40 \mathrm{~cm})$ with potted eggplant seedlings as substrate for oviposition, and fed honey solution (ad libitum). Seedlings were replaced every $2 \mathrm{~d}$, their leaves were removed and placed in plastic boxes (13 cm in width, $18 \mathrm{~cm}$ in length, $5 \mathrm{~cm}$ in height) covered at the top with voile, to rear the larvae until pupae formation. The obtained pupae were incorporated into the colony. P. dignus adults were placed in plastic containers (22 cm in diameter, $25 \mathrm{~cm}$ in height) and provided with eggplant seedlings infested with T. absoluta larvae for parasitization. After $48 \mathrm{~h}$ of exposure, seedlings were removed and their leaves were placed in plastic boxes as described above, to rear the larvae until host pupae or parasitoid cocoon were formed. T. absoluta pupae were incorporated into the colony and P. dignus cocoons were either stocked individually in Petri dishes until adult emergence and then added into the colony or used in the trials.

\section{DevelopmentalTime of Immature Stages and Adult Longevity}

$P$. dignus life-history attributes when parasitizing T. absoluta in tomato plants were determined elsewhere (Luna et al. 2007, Nieves et al. 2015). To assess differences in life parameters when the pest attacks eggplant, an experiment was set up. Newly emerged adult wasps were selected from the above-mentioned colony (one female $x$ $\approx$ five males) and observed until mating in plastic mating chambers ( $8 \mathrm{~cm}$ diameter, $10 \mathrm{~cm}$ height), which occurred within the first $5 \mathrm{~h}$ of observation. After this, each female $(n=12)$ was individually transferred into a plastic container $(22 \mathrm{~cm}$ in diameter, $25 \mathrm{~cm}$ in height).
Each female was offered one eggplant seedling 20-cm height, previously infested with $20 \mathrm{~T}$. absoluta third-instar larvae, and supplied with honey droplets and water ad libitum. After $24 \mathrm{~h}$ of exposure, T. absoluta infested leaves from each experimental unit were placed into plastic boxes as described above, and larvae were fed every $72 \mathrm{~h}$ by supplying new eggplant leaves. Boxes were put inside Ziploc bags to prevent larval escape. Daily, the units were checked to register host larvae mortality, and formation of T. absoluta pupae or $P$. dignus cocoons, using a stereoscopic microscope (SMZ 1270, Nikon Corporation, Tokyo, Japan). Parasitoid cocoons were individually stored in Petri dishes, and monitored daily until adult emergence for sex determination.

The developmental times from egg to pupa and from pupa to adult of $P$. dignus were determined by counting the total number of days from the time of parasitization until cocoon formation, and then from cocoon formation until adult emergence.

Newly emerged adults of both sexes were used to assess their longevity. To determine female longevity the following aspects were taken into account: 1$)$ the better performance when $P$. dignus parasitizes mid-instar host larvae; and 2) parasitoid female life span is influenced -among other factors- by the availability of hosts throughout its life (Quicke 1997). Then, in this experiment, $2^{\text {nd }}$ and $3^{\text {rd }}$ instars of T. absoluta larvae were provided to wasps ad libitum. For estimating male longevity, individuals were only fed with honey and water. Individuals of both sexes were monitored until death.

Differences in immature development times and adult longevity data (mean \pm SEM), between sexes, were compared using Student's $t$-tests with a significance value of $P<0.05$, by using the Bipartite package in the $\mathrm{R}$ environment for statistical computing (R Development Core Team 2014).

\section{Daily Parasitism Rate}

Newly emerged $P$. dignus adults were selected from the colony and allowed to mate by grouping one female $x \approx$ five males in individual mating chambers. Then, mated females $(n=10)$ were individually transferred into plastic containers $(22 \mathrm{~cm}$ in diameter, $25 \mathrm{~cm}$ in height). As females do not show pre-oviposition period (Nieves et al. 2015), a potted eggplant seedling containing approximately 15 T. absoluta larvae $-2^{\text {nd }}$ and $3^{\text {rd }}$ instars, already installed in mineswas offered daily for parasitization, from the first day of adult emergence until its death. Adult females were daily provided with honey droplets and water ad libitum. Each day, infested seedling leaves were removed, placed into plastic boxes, and checked every $48 \mathrm{~h}$ to record the formation of moth pupae or parasitoid cocoons. Leafminers were fed with fresh eggplant leaves from the greenhouse.

The following biological parameters were determined: 1) The reproductive period: the mean $\left({ }_{ \pm} \mathrm{SEM}\right)$ number of days a $P$. dignus female parasitized hosts; 2) The daily parasitism rate per female, calculated as the mean $\left({ }_{ \pm} \mathrm{SEM}\right)$ number of cocoons obtained in relation to the number of hosts offered; and, 3) The sex ratio of the offspring: the proportion of females emerged (number of females/number of females + males).

\section{Functional Response}

Newly emerged (less than 3-d-old) adults of both sexes from the colony were grouped as described above, to allow mating. Next, females were immediately transferred to plastic containers $(22 \mathrm{~cm}$ in diameter, $25 \mathrm{~cm}$ in height) and offered hosts at five densities: 3,7 , $10,15,20$, or 25 second and third instar T. absoluta larvae, installed in potted eggplant seedlings. The range of densities tested in this trial was selected according to a previous study on P. dignus functional 
response in tomato (Luna et al. 2007), and also considering the population parameters registered for this parasitoid (Nieves et al. 2015). Ten replicates were carried out for each host density. The experiment lasted $24 \mathrm{~h}$, and then, infested leaves with exposed larvae were removed and disposed in labeled plastic boxes with fresh eggplant leaves until T. absoluta pupae or $P$. dignus cocoon formation.

Number $\left(N_{p}\right)$ and proportion $\left(N_{p} / N_{0}\right)$ of parasitized hosts at each host density offered $\left(N_{0}\right)$ were calculated to determine type I, II and III functional response curves, described by Holling (1959). For doing so, the logistic model was fit to the data through stepwise nonlinear regressions between the proportion of parasitized hosts and host density (Trexler et al. 1988, Juliano 2001, Fernández Arhex and Corley 2004, Luna et al. 2007).

The significance of coefficients was calculated using the maximum likelihood method Statistical program R (R Development Core Team 2014).

Since both the quadratic and cubic expressions were not significant, the instantaneous parasitism rate $\left(a^{\prime}\right)$ (sensu the 'attack rate' by Holling 1959) of the parasitoid, i.e., the proportion of host parasitized by time unit, was calculated by linear regression using the following equation:

$$
N_{\mathrm{p}}=a^{\prime} T N_{0}
$$

where: $T$ is the time that hosts were exposed to the parasitoid female (24h).

\section{Results}

\section{DevelopmentalTimes of Immature Stages and Adult} Longevity

P. dignus developmental times for females and males assessed on the T. absoluta-eggplant system are shown in Table 1 . There were not significant differences between sexes (egg-pupa: $t=0.09 ; \mathrm{df}=148$, $P=0.92$; pupa-adult: $t=0.02 ; \mathrm{df}=148, P=0.98$; egg-adult: $t=0.08$; $\mathrm{df}=148, P=0.93)$. Adult longevity did not differ between sexes; on average it was of ca. $24 \mathrm{~d}(t=1.18 ; \mathrm{df}=48, P=0.24)$.

\section{Daily Parasitism Rate}

Females did not show a pre-oviposition period and usually did not exhibit a post-oviposition period, laying eggs until their death. The reproductive period lasted $18.5 \pm 0.5 \mathrm{~d}$. The maximum daily percentage of parasitism was $50 \%$ and it was reached at the first day of female adult emergence, then decreased and remained fairly constant until the 20th day (Fig. 1). P. dignus females produced $61.3 \pm 5.23$ cocoons. The sex ratio was biased towards females (0.7).

Table 1. Life history attributes of $P$. dignus when parasitizing T. absoluta larvae, fed with eggplant (Solanum melongena L.) leaves, assessed under laboratory conditions $\left(25 \pm 2^{\circ} \mathrm{C}, 65 \pm 5 \%\right.$ $\mathrm{RH}, 14: 10[\mathrm{~L}: \mathrm{D}] \mathrm{h})$

\begin{tabular}{lccccc}
\hline Attributes & Females & $n$ & Males & $n$ & $t$-test \\
\hline $\begin{array}{l}\text { Developmental time } \\
\text { Mean } \pm \text { SEM (d) }\end{array}$ & & 64 & & 86 & \\
$\quad$ Egg-pupa & $15.56 \pm 0.30$ & & $15.38 \pm 0.25$ & & $\mathrm{~ns}$ \\
$\quad \begin{array}{l}\text { Pupa-adult } \\
\quad \text { Egg-adult }\end{array}$ & $12.33 \pm 0.23$ & & $12.32 \pm 0.19$ & & $\mathrm{~ns}$ \\
$\begin{array}{l}\text { Adult longevity } \\
\quad \text { Mean } \pm \text { SEM (d) }\end{array}$ & $24.83 \pm 0.37$ & & $27.51 \pm 0.35$ & & $\mathrm{~ns}$ \\
& 32 & & 18 & \\
\hline
\end{tabular}

ns: not significant differences at $P<0.05$.

\section{Functional Response}

The number of T. absoluta larvae parasitized by P. dignus increased linearly with host density and it was highly variable at all densities (Fig. 2). The maximum value of T. absoluta larvae attacked by a single P. dignus female in $24 \mathrm{~h}$ was 10 , at a density level of 25 hosts. The proportion of parasitized T. absoluta larvae was also highly variable and independent of the host density tested (Fig. 3). Logistic regression parameters showed a Type I functional response, since cubic and quadratic coefficients (Type II and III, respectively) were not significant (Table 2). Linear regression parameters were: $y=0.22+0.24 x ; r^{2}=0.4 ; F=46.35 ; \mathrm{df}=1,58 ; P<0.001$, indicating an instantaneous attack rate $\left(a^{\prime}\right)$ of 0.24 attacked larvae/ available larvae, in $24 \mathrm{~h}$.

\section{Discussion}

In this paper we report for the first time some biological attributes of the solitary larval endoparasitoid $P$. dignus, when parasitizing the South American tomato moth in eggplant. We emphasize those traits having implications for the biological control of this pest in horticultural greenhouse crops. Considering that this parasitoid is being evaluated as a biocontrol agent of T. absoluta in tomato, to be used by conservation or augmentative methods (Luna et al. 2007,

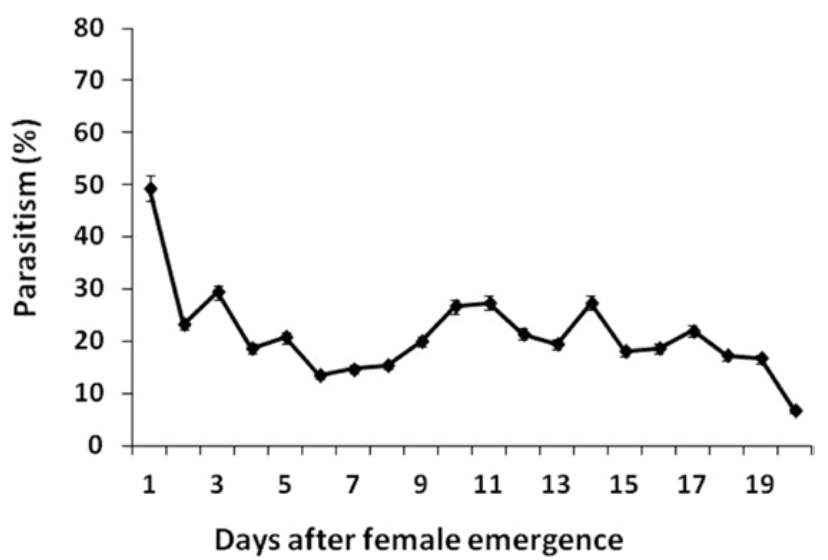

Fig. 1. Daily parasitism rate (mean $\pm \mathrm{SE}$ ) over the lifetime of $P$. dignus females attacking $T$. absoluta larvae in eggplant.

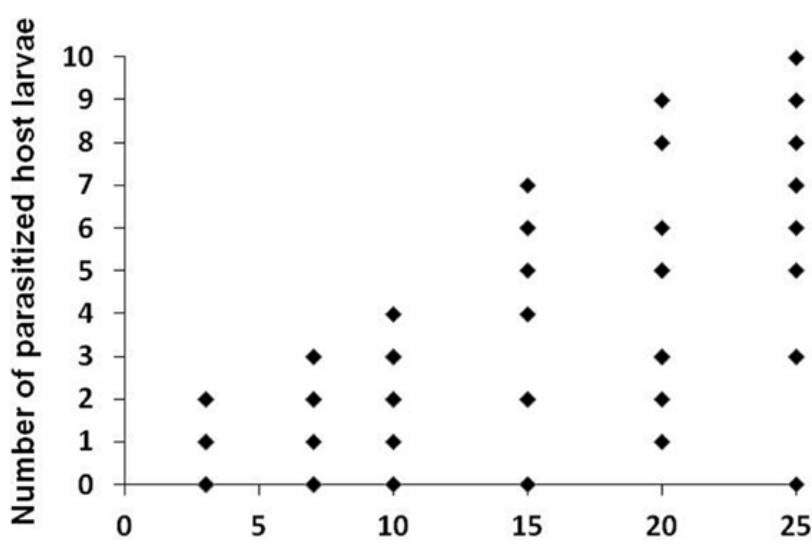

Density of Tuta absoluta larvae

Fig. 2. Relationship between the number of $T$. absoluta larvae parasitized by $P$. dignus, at different host densities offered. 


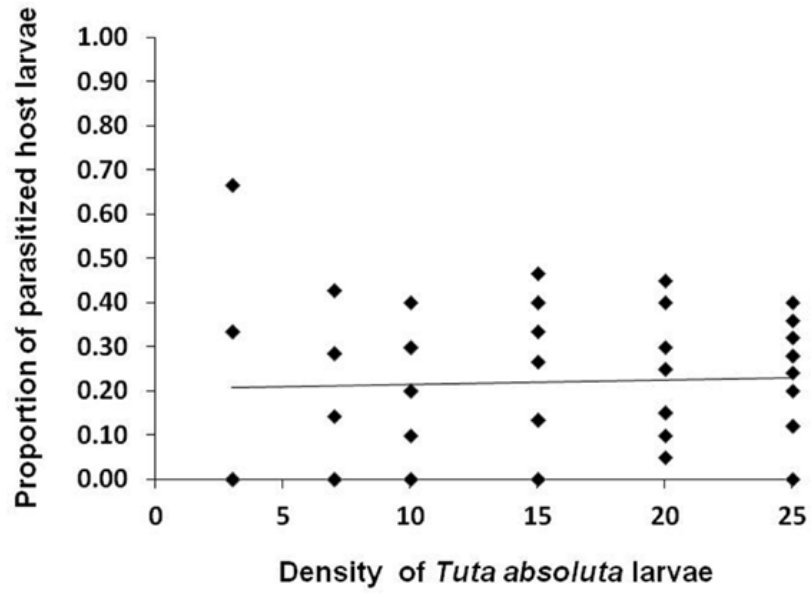

Fig. 3. Type I functional response of $P$. dignus at different densities of T. absoluta larvae. The equation is shown in the text.

Sánchez et al. 2009, Nieves et al. 2015, Salas Gervassio et al. 2016), results of the present study contributes new knowledge to promote its manipulation in other solanaceous crops.

When comparing developmental times of P.dignus with those recorded in tomato (Nieves et al. 2015), it can be observed that from egg to adult emergence it took $\approx 5$ more days, while adult longevity was slightly shorter for females $(\approx 2 \mathrm{~d})$, but similar to males when parasitizing T. absoluta on eggplant.

In relation to the reproductive period, it was longer than that observed in tomato ( $\approx 4$ d) (Luna et al. 2007, Nieves et al. 2015), with a higher cocoon production than that reported by Luna et al. (2007) (32 cocoons per female) in tomato. However, it should be noted that the lower number of hosts offered to the parasite in the tomato experiment could have limited, at least in part, the rate of female oviposition.

The parasitism rate of $P$. dignus found in this study appears to be quite important when compared to that of other T. absoluta larval parasitoids. Biondi et al. (2013) reported for the female of the larval ectoparasitoid Bracon nigricans (Szépligeti; Hymenoptera: Braconidae), had a much lower performance than that of $P$. dignus. This common natural enemy of T. absoluta in European crops produced an average of 29.8 offspring, and reached a maximum weekly parasitism rate of $1.8( \pm 0.09)$. However, B. nigricans could be considered a suitable biological control agent since it causes high mortality in the host population ( $70 \%$ of available larvae) due to high rates of nonreproductive killing behavior (host-feeding).

Other braconid species have been pointed out as potential agents for biological control but with a lower performance than $P$. dignus. For example, Spathius galinae (Belokobylskij and Strazenac; Hymenoptera: Braconidae), is a larval parasitoid of the emerald ash borer Agrilus plannipennis (Fairmaire; Coleoptera: Buprestidae), and it is currently being evaluated for field releases in the United States to control this buprestid (Gould and Duan 2013, Duan et al. 2014). The female of $S$. galinae produced an average of $47( \pm 5.3)$ eggs throughout its lifespan and weekly parasitism rates ranged from $39 \%$ to less than $25 \%$.

The female biased sex ratio was similar to that obtained by Luna et al. (2007) in tomato, while Cardona and Oatman (1971) found a sex ratio deviated to males when P. dignus is reared on other gelechiid, Keiferia lycopersicella (Walsingham; Lepidoptera: Gelechiidae), under laboratory conditions. A female-biased sex ratio is considered a beneficial trait for hymenopteran biocontrol agents, since females are
Table 2. Results of the logistic regression analyses of the proportion of $T$. absoluta larvae parasitized by $P$. dignus in relation to different host densities $(3,7,10,15,20$, or 25 second- to thirdinstar larvae) offered in potted eggplant seedlings, during a 24-h experiment

\begin{tabular}{|c|c|c|c|c|}
\hline Parameter & Estimator & Standand error & Wald & $P$ \\
\hline \multicolumn{5}{|c|}{ Cubic expression } \\
\hline Intercept & -1.07 & 0.89 & -1.2 & 0.23 \\
\hline$N_{0}$ & -0.08 & 0.22 & -0.39 & 0.69 \\
\hline$N_{0}^{2}$ & 0.007 & 0.015 & 0.45 & 0.65 \\
\hline$N_{0}^{3}$ & -0.0001 & 0.0003 & -0.45 & 0.65 \\
\hline \multicolumn{5}{|c|}{ Quadratic expression } \\
\hline Intercept & -1.41 & 0.5 & -2.8 & 0.0005 \\
\hline$N_{0}$ & 0.007 & 0.07 & 0.10 & 0.92 \\
\hline$N_{0}^{2}$ & 0.00007 & 0.002 & 0.03 & 0.97 \\
\hline \multicolumn{5}{|c|}{ Linear expression } \\
\hline Intercept & -1.42 & 0.24 & -5.82 & 5.7 e- 09 \\
\hline$N_{0}$ & 0.009 & 0.01 & 0.72 & 0.47 \\
\hline
\end{tabular}

responsible of attacking hosts (Wajnberg et al. 2008). Besides, an offspring deviated to females can be another advantageous condition for mass rearing and the use of $P$. dignus through augmentative releases, as reported for many arrhenotokous braconid species (Green et al. 1982, Luck et al. 1999, Dannon et al. 2010). It could therefore be suggested that the highest proportion of females in P. dignus offspring exhibited in eggplant—as in tomato-contributes to the performance of this parasitoid as a biocontrol agent of T. absoluta.

The type-I functional response of $P$. dignus displayed when attacking T. absoluta in eggplant is coincident with that found in tomato, and the attack rates were similar in both solanaceous plants (Luna et al. 2007). Coincidently, Savino et al. (2012) reported that Dineulophus phthorimaeae (de Santis; Hymenoptera: Eulophidae), a larval ectoparasitoid coexisting with $P$. dignus in tomato and eggplant crops in the main horticultural regions of Argentina (Salas Gervassio et al. 2016), exhibited a type-I functional response and a similar attack rate $\left(a^{\prime}=0.22\right)$ to $P$. dignus.

$P$. dignus showed density independent parasitism in the solanaceous species studied, and this attribute could be explained by its foraging behavior. As it was discussed in Luna et al. (2007), we suggested that $P$. dignus behaves as a time-limited species when interacting with T. absoluta in a fixed-time experiment.

The attack rate of a parasitoid provides a valuable measure of its parasitism efficiency and its potential for successful biological control. van Lenteren and Manzaroli (1999) pointed out that a parasitoid can be an effective biological control agent if, in addition to other factors, its $r_{\mathrm{m}}$ and kill rate are equal or greater than the $r_{\mathrm{m}}$ of the targeted pest. In this sense, P.dignus exhibited an $r_{\mathrm{m}}=0.14$ (Nieves et al. 2015) equal to that of T. absoluta's $\left(r_{\mathrm{m}}=0.14\right.$; Pereyra and Sánchez 2006) and instantaneous attack rates higher than $r_{\mathrm{m}}$ of the pest in both solanaceous plants.

Results of this study suggest that $P$. dignus, in spite of differences in some life history traits, would have a similar performance in tomato and eggplant in terms of its efficacy in the control of T. absoluta. Further field studies aimed to design strategies for manipulating this parasitoid could provide growers with an alternative tool for T. absoluta control in both crops.

\section{Acknowledgments}

We thank Marcelo Maita, Susana Parrillo, and other producers for kindly allowing us to work at their farms. Eliana Nieves and Maximiliano Rocchi 
provided insect rearing and experimental follow-up assistance. Graciela Minardi helped with statistical analyses. Laura Morote helped with graphical design. This research was funded by CONICET (PIP 0112), ANPCyT (PICT 2012-1624) and PID UNLP (N706). The anonymous referees and the subject editor kindly helped with useful comments which have significantly improved the paper.

\section{References Cited}

Bawin, T., D. Dujeu, L. De Baker, M. L. Fauconnier, G. Lognay, P. Delaplace, F. Francis, and F. J. Verheggen. 2015. Could alternative solanaceous hosts act as refuges for the tomato leafminer, Tuta absoluta? Arth. Plant Interact. 4: 425 .

Biondi, A., N. Desneux, E. Amiens-Desneux, G. Siscaro, and Zappala, L. 2013. Biology and developmental strategies of the palearctic parasitoid Bracon nigricans (Hymenoptera: Braconidae) on the neotropical moth Tuta absoluta (Lepidoptera: Gelechiidae). J. Econ. Entomol. 106: 1638-1647.

Cardona, C., and R. Oatman. 1971. Biology of Apanteles dignus (Hymenoptera: Braconidae), a primary parasite of the tomato pinworm. Ann. Entomol. Soc. Am. 64: 996-1007.

Colomo, M. V., D. C. Berta, and M. J. Chocobar. 2002. El complejo de himenópteros parasitoides que atacan a la "polilla del tomate" Tuta absoluta (Lepidoptera: Gelechiidae) en la Argentina. Acta Zoologica Lilloana 46: 81-92.

Dannon, E. A., M. Tamo, A. van Huis, and M. Dicke. 2010. Functional response and life history parameters of Apanteles taragamae, a larval parasitoid of Marucavitrata. Bio. Control 55: 363-378.

Desneux, N., E. Wajnberg, K. A. G. Wyckhuys, G. Burgio, S. Arpaia, C. A. Narvaez-Vasquez, J. Gonzalez-Cabrera, D. Catalan Ruescas, E. Tabone, J. Frandon, J. Pizzol, C. Poncet, T. Cabello, and A. Urbaneja. 2010. Biological invasion of European tomato crops Tuta absoluta: ecology, history of invasion and prospects for biological control. J. Pest Sci. 83: 197-215.

Desneux, N., M. G. Luna, T. Guillemaud, and A. Urbaneja. 2011. The invasive South American tomato pinworm, Tuta absoluta, continues to spread in Afro-Eurasia and beyond: the new threat to tomato world production. J. Pest Sci. 84: 403-408.

Duan, J. J., T. J. Watt, and K. Larson. 2014. Biology, life history, and laboratory rearing of Spathius galinae (Hymenoptera: Braconidae), a larval parasitoid of the invasive emerald ash borer (Coleoptera: Buprestidae). J. Econ. Entomol. 107: 939-946.

El Arnaouty, S. A., and M. N. Kortam. 2012. First record of the mirid predatory species, Nesidiocoris tenuis Reuter (Heteroptera: Miridae) on the tomato leafminer, Tuta absoluta (Meyrick) (Lepidoptera: Gelechiidae) in Egypt. Egypt. J. Biol. Pest Co. 22: 223-224.

Estay, P. 2000. Polilla del tomate Tuta absoluta (Meyrick). Instituto de Investigationes Agropecuarias, Centro Regional de Investigacion La Platina, Ministerio de Agricultura Santiago Chile. http://www.inia.cl/ medios/biblioteca/informativos/NR25648.pdf.

Fernández Arhex, V., and Corley, J. C. 2004. La respuesta funcional: una revisión y guía experimental. Asociación Argentina de Ecología. Ecología Austral 14: 83-93.

Fernández-Triana, J. L., D. H. Janzen, W. Hallwachs, J. B. Whitfield, M. A. Smith, and R. Kula. 2014. Revision of the genus Pseudapanteles (Hymenoptera, Braconidae, Microgastrinae), with emphasis on the species in area de Conservación Guanacaste, northwestern Costa Rica. Zoo. Keys 446: 1-82.

Galarza, J. 1984. Laboratory assessment of some Solanaceous plants as possible food plants of tomato moth Scrobipalpula absoluta. 3 IDIA 421/424: 30-32.

Gould, J. R., and J. J. Duan. 2013. Petition for release of an exotic parasitoid, Spathius galinae Belokobylskij \& Strazanac, for the biological control of the emerald ash borer, Agrilus planipennis Fairmaire. U.S. Dept. Agric. APHIS Petition 01.

Green, R. F., G. Gordh, and B. A. Hawkins. 1982. Precise sex ratios in highly inbred parasitic wasps. Amer. Nat. 120: 653-665.

Holling, C. S. 1959. Some characteristics of simple types of predation and parasitism. Can. Entomol. 91: 385-398.
Juliano, S. A. 2001. Non linear curve fitting. Predation and functional response curves, pp. 178-197. In S. M. Scheiner and J. Gurevitch (eds.), Design and Analysis of Ecological Experiments, 2nd ed. University Press, Oxford.

Luck, R. F., B. M. Shepard, and P. E. Kenmore. 1999. Evaluation of biological control with experimental methods, pp. 225-242. In T. S. Bellows and T. W. Fisher (eds.), Handbook of biology control. Academic Press, New York.

Luna, M. G., N. E. Sánchez, and P. C. Pereyra. 2007. Parasitism of Tuta absoluta (Lepidoptera: Gelechiidae) by Pseudapanteles dignus (Hymenoptera: Braconidae) under laboratory conditions. Environ. Entomol. 36: 887-893.

Luna, M. G., P. C. Pereyra, C. E. Coviella, E. Nieves, V. Savino, N. G. Salas Gervassio, E. Luft, E. Virla, and N. E. Sanchez. 2015. Potential of biological control agents against Tuta absoluta (Lepidoptera:Gelechiidae): current knowledge in Argentina. Fla. Entomol. 98: 489-494.

Mohamed, E. S. I., M. E. Mohamed, and S. A. Gamiel. 2012. First record of the tomato leafminer, Tuta absoluta (Meyrick) (Lepidoptera: Gelechiidae) in Sudan. OEPP/EPPO Bull. 42: 325-327.

Nieves, E., P. C. Pereyra, M. G. Luna, P. Medone, and N. E. Sanchez. 2015. Laboratory population parameters and field impact of the larval endoparasitoid Pseudapanteles dignus (Hymenoptera: Braconidae) on its host Tuta absoluta (Lepidoptera: Gelechiidae) in tomato crops in Argentina. J. Econ. Entomol. 108: 1553-1559.

Parra, J. R. P., and R. A. Zuchi. 2004. Trichogramma in Brazil: feasibility of use after twenty years of research. Neotrop. Entomol. 33:271-281.

Pereyra, P. C., and N. E. Sanchez. 2006. Effect of two solanaceous plants on developmental and population parameters of the tomato leafminer, Tuta absoluta (Meyrick) (Lepidoptera: Gelechiidae). Neotrop. Entomol. 35: 671-676.

Ponti, L, A. P. Gutierrez, and M. A. Altieri. 2015. Holistic approach in invasive species research: The case of the tomato leaf miner in the Mediterranean Basin. Agroecol. Sust. Food. 39:436-468.

Quicke, D. L. J. 1997. Parasitic wasps. Chapman \& Hall, London.

R Development Core Team. 2014. R: a language and environment for statistical computing. R Foundation for Statistical Computing, Vienna, Austria. http://www.Rproject.org.

Salas Gervassio, N. G., M. G. Luna, S. Lee, A. Salvo, and N. E. Sánchez. 2016. Trophic web associated with the South American tomato moth Tuta absoluta: implications for its conservation biological control in Argentina. Agric. For. Entomol. 18: 137-144.

Sánchez, N. E., P. C. Pereyra, and M. G. Luna. 2009. Spatial patterns of parasitism of the solitary parasitoid Pseudapanteles dignus (Muesebeck) (Hymenoptera: Braconidae) on the tomato leafminer Tuta absoluta (Meyrick) (Lepidoptera:Gelechiidae). Environ. Entomol. 38: 365-374.

Savino, V., C. E. Coviella, and M. G. Luna. 2012. Reproductive biology of Dineulophus phhtorimaeae De Santis (Hymenoptera: Eulophidae), a natural enemy of the tomato moth Tuta absoluta (Meyrick)(Lepidoptera: Gelechiidae). J. Insect Sci. 12: 153.

Savino, V., M. G. Luna, N. G. Salas Gervassio, and C. Coviella. 2016. Interspecific interactions between two Tuta absoluta (Lepidoptera: Gelechiidae) larval parasitoids with contrasting life histories. Bull. Entomol. Res. 107: 32-38.

Speranza, S., E. Virla, and P. Huemer. 2009. Attacchi de Tuta absoluta: riconoscerla per gestirla. Terra e Vita 25: 44-47.

Trexler, J. C., E. M. Charles, and J. Travis. 1988. How can the functional response best be determined? Oecologia 76: 206-214.

Tropea Garzia, G., A. Colombo, G. Siscaro, and G. Campo. 2009. Rinvenuta in Sicilia Tuta absoluta. L'Informatore Agrario 65: 71.

Urbaneja, A., R. Vercher, V. Navarro, F. García Marí, and J. L. Porcuna. 2007. La polilla del tomate Tuta absoluta. Phytoma 194: 16-23.

(USDA) U.S. Department of Agriculture. 2011. New pest response guidelines tomato leafminer (Tuta absoluta). USDA-APHIS-PPQ-EDP Emergency Management, Riverdale, MD.

van Lenteren, J. C., and Manzaroli, G. 1999 Evaluation and use of predators and parasitoids for biological control of pests in greenhouses. In R. Albajes, M. Lodovica Gullino, J. C. van Lenteren, and Y. Elad (eds.), Integrated pest and disease management in greenhouse crops. Developments in plant pathology, vol 14. Springer, Dordrecht.

Wajnberg, E., C. Bernstein, and J. van Alphen. 2008. Behavioral ecology of insect parasitoids. Blackwell Publishing, Malden, MA, USA. 